\title{
Venous thromboembolism - multifactorial disease. Case report of a 36-year-old woman
}

\section{Żylna choroba zakrzepowo-zatorowa - schorzenie uwarunkowane wieloczynnikowo. Opis przypadku 36-letniej kobiety}

\author{
Łukasz Turek ${ }^{1}$, Anna Polewczyk ${ }^{1,2}$, Marianna Janion ${ }^{1,2}$ \\ ${ }^{1} 2^{\text {nd }}$ Department of Cardiology, Swietokrzyskie Cardiology Centre, Kielce, Poland \\ Head of the Department: Prof. Marianna Janion MD, PhD \\ 2Faculty of Medicine and Health Sciences, Jan Kochanowski University, Kielce, Poland \\ Head of the Faculty: Prof. Marianna Janion MD, PhD
}

Venous thromboembolism (VTE) is a condition that includes both deep vein thrombosis (DVT) and pulmonary embolism (PE). Venous thromboembolism is the third most common cardiovascular disease, after myocardial infarction and stroke, among the general population. The overall annual incidence of VTE is estimated to be 1-2 per 1000 adults per year. Venous thromboembolism is a multifactorial disease with both inherited and acquired risk factors. In 26$47 \%$ of first-time VTE cases the aetiology is unknown [1]. The main symptoms reported by patients are dyspnoea, chest pain and cough, unilateral extremity swelling, and unilateral leg pain. In most patients, deterioration of health withdraws after treatment and never returns, but in some people recurrence of VTE is reported [2]. We present the case report of a 36-yearold female with venous thromboembolism.
We describe the case report of a 36-year-old woman with venous thromboembolism, in whom initial presentation was pain and tenderness of right lower limb, syncope, and breathlessness. An abnormal condition was preceded by $9 \mathrm{~h}$ of immobilisation due to sitting in a car. The 36-year-old woman had been diagnosed with polycystic ovary syndrome (PCOS) a few years previously, so she was currently treated with monophasic combined oral contraceptive (COC) (drospirenone $(3 \mathrm{mg})$ with ethinyl oestradiol $(30 \mu \mathrm{g})$ for 4 years (long-term treatment)). The patient had no history of smoking or alcohol abuse and no family history of cardiovascular diseases. The ECG demonstrated sinus tachycardia and an SI, QIII, TIII pattern (Figure 1) suggestive of pulmonary embolisation, and anterior and inferior wall ischaemic myocardium. Physical examination revealed normal blood pressure

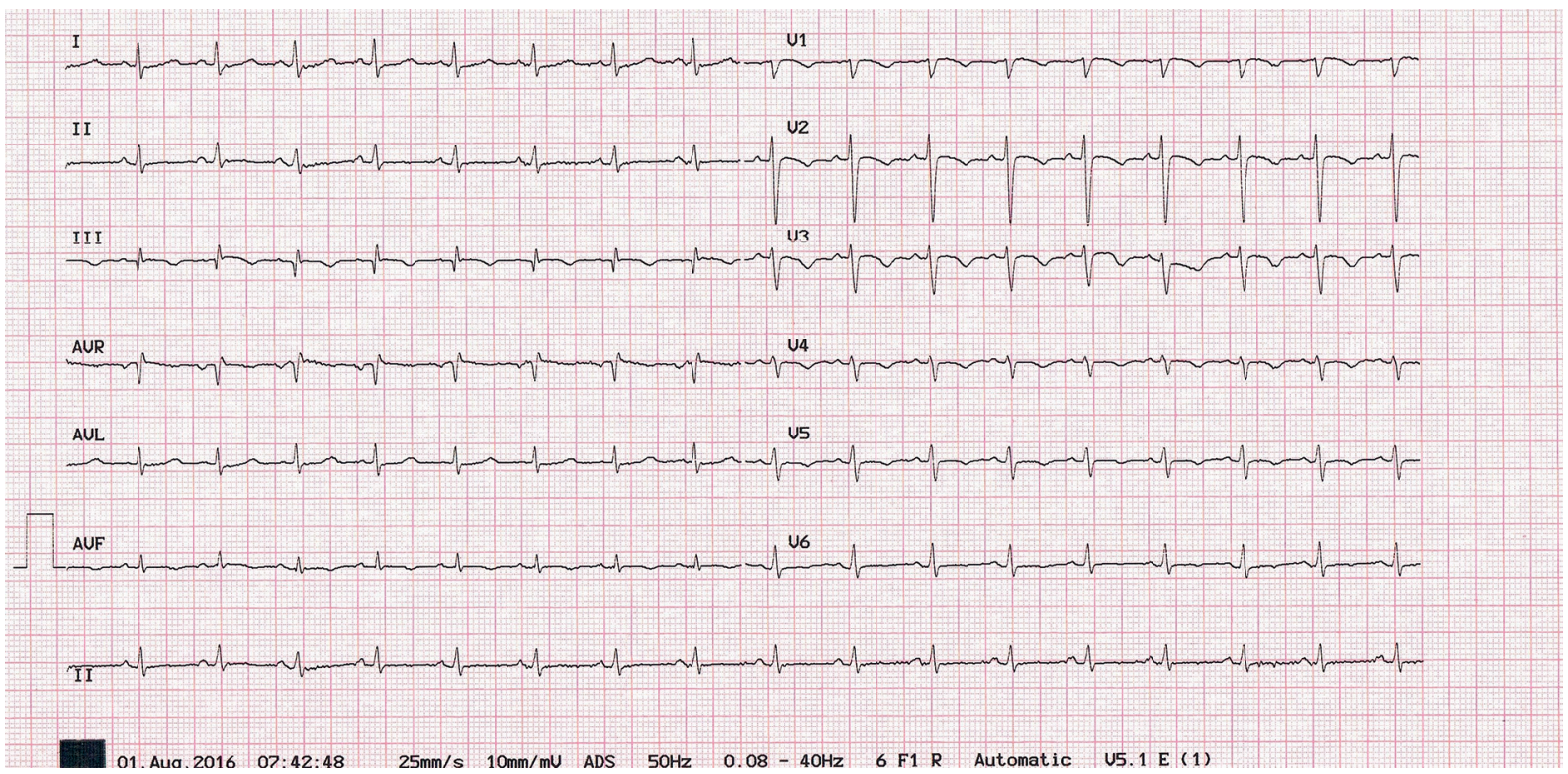

Figure 1. Electrocardiogram - on admission to the hospital 


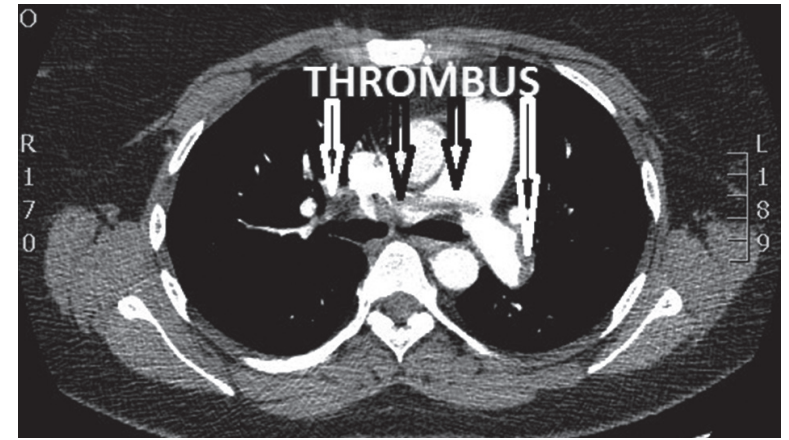

Figure 2. Computed tomography angiography of pulmonary arteries - pulmonary embolism

(BP - 120/80 mm Hg), tachycardia (105 bpm), tachypnoea (rate 26), tenderness of right lower limb, and overweight $\left(\mathrm{BMI}=28.9 \mathrm{~kg} / \mathrm{m}^{2}\right)$; otherwise, there were no deviations from the norm in physical examination. Arterial blood gas (ABG) analysis was done on admission, which identified reduced oxygen partial pressure $\left(\mathrm{pO}_{2}=64 \mathrm{~mm} \mathrm{Hg}\right)$, lowered partial pressure of carbon dioxide $\left(\mathrm{pCO}_{2}=30 \mathrm{~mm} \mathrm{Hg}\right)$, and reduced arterial oxyhaemoglobin saturation $\left(\mathrm{SaO}_{2}=94 \%\right)$. Other laboratory examinations showed normal morphology and inflammatory parameters, and elevated values of troponin T (83.8 ng/l), D-dimer (7796 $\mu \mathrm{g} / \mathrm{l})$, and B-type natriuretic peptide $(\mathrm{BNP}=399 \mathrm{pg} / \mathrm{ml})$. Our patient excluded the possibility of pregnancy and this was confirmed in a quantitative $\beta$-human chorionic gonadotropin ( $\beta$-hCG) blood test. In connection with high clinical probability of pulmonary embolism (Wells' Criteria for Pulmonary Embolism 7.5 points; Revised Geneva Score for Pulmonary Embolism - 12 points) for patients without shock or hypotension, an initial parenteral anticoagulation with low-molecular-weight heparin (LMWH) was administered while further diagnostic work-up was in progress [2]. Then CT angiography of pulmonary arteries was performed, and it showed embolus riding at the bifurcation of the main pulmonary artery branches (saddle embolus) and clots in the lobar pulmonary artery branches, which confirmed PE (Figure 2). Moreover, compression venous ultrasonography (CUS) of the left lower limb revealed proximal deep vein thrombosis. A study using transthoracic echocardiography (TTE) showed disturbed right ventricular (RV) ejection pattern ("60/60 sign" - which is defined as an RV acceleration time (AcT) $\leq 60 \mathrm{~ms}$ in presence of tricuspid regurgitation pressure gradient (TRPG) $\leq 60 \mathrm{~mm} \mathrm{Hg}$ ); in our patient the RV AcT was $41 \mathrm{mil}$ liseconds with mid-systolic deceleration of flow velocity in the RV outflow tract (Figure 3) and the TRPG was $42 \mathrm{~mm} \mathrm{Hg}$. The calculated systolic pulmonary artery pressure (SPAP) using equation SPAP $=$ TRPG + right arterial pressure (RAP) was $45 \mathrm{~mm} \mathrm{Hg}$, and we have found the presence of McConnell's sign (RV dysfunction with characteristic sparing of the apex). In order to perform risk stratification of the patient with acute pulmonary embolism the Pulmonary Embolism Severity Index (PESI) was calculated. Finally our patient with acute PE in PESI Class I, with elevated cardiac biomarkers (elevated troponin T concentrations in plasma and elevated B-type natriuretic peptide concentrations in plasma) and with signs of RV dysfunction on imaging tests (TTE), was classified into the intermediate-low-risk category of early (in-hospital or 30-day) mortality risk [2]. When pulmonary embolism was objectively confirmed, treatment with weight-adjusted LMWH was continued, and from the fourth day after the diagnosis of pulmonary embolism the anticoagulation with LMWH was changed to single oral drug treatment with the direct factor Xa inhibitor rivaroxaban (15 $\mathrm{mg}$ twice daily for 3 weeks - including for this period time of anticoagulation with LMWH, followed by $20 \mathrm{mg}$ once daily) [2]. As a result of the anticoagulant treatment, in this patient a gradual clinical improvement was observed, as well as resolution of tachycardia, tachypnoea, SI, QIII, TIII pattern in the ECG, McConnell's sign and

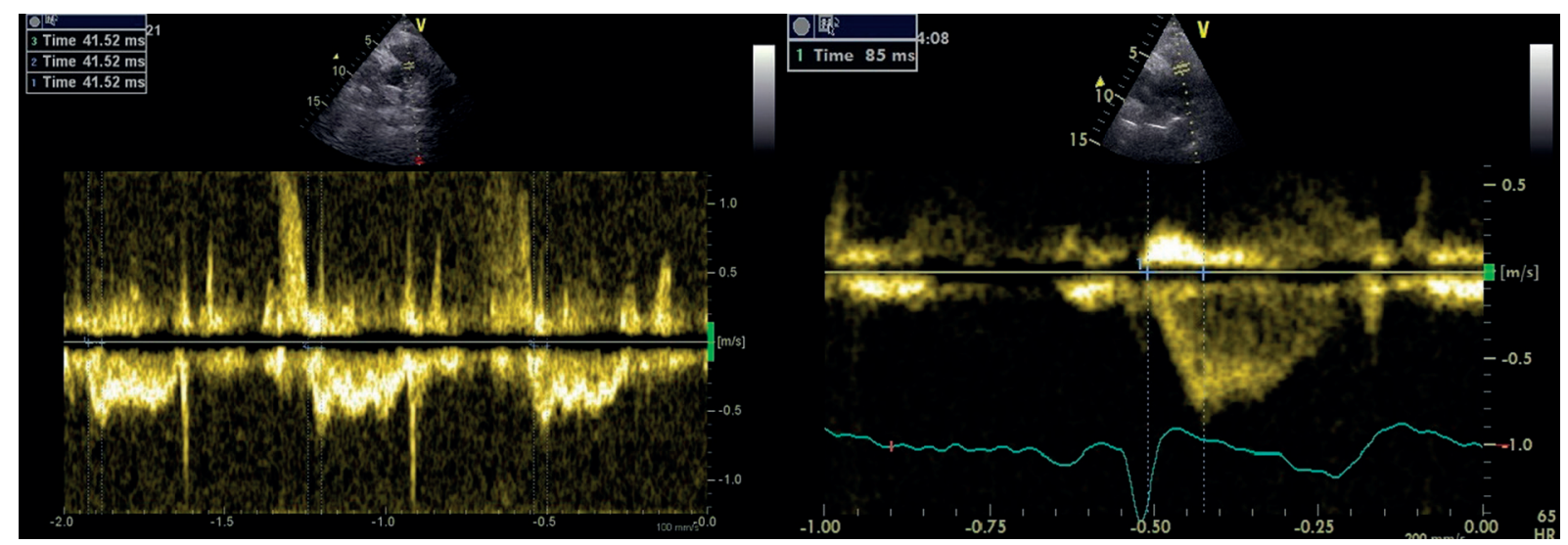

Figure 3. Echocardiography study: parasternal short-axis view - base. Right ventricular ejection pattern. On the left side - before anticoagulation. On the right side - during anticoagulant therapy 
"60/60 sign" in echocardiography, and decreased values of troponin T, D-dimer, and BNP. In good general condition, patient discharged home with the recommendation to continue oral anticoagulant therapy with rivaroxaban for at least three months [2] and the use of oral combined hormonal pill was banned, as an unacceptable health risk.

In 1884, Rudolph Virchow first proposed that thrombosis was the result of at least one of three underlying aetiological factors: vascular endothelial damage, stasis of blood flow, and hypercoagulability [3] - collectively known as Virchow's triad. Nowadays, on the basis of evidence, although Virchow's triad for thrombogenesis is the major factor promoting the formation of thrombosis, there are other known medical conditions like systemic inflammation that have been closely associated with an increased risk of VTE [4]. Venous thromboembolism is considered to be a consequence of the interaction between patient-related usually permanent - risk factors and setting-related - usually temporary - risk factors. This abnormal condition is thought to be provoked in the presence of a temporary or reversible risk factor (such as surgery, trauma, immobilisation, pregnancy, and oral contraceptive use or hormone replacement therapy) within the last 6 weeks to 3 months before diagnosis, and unprovoked in the absence thereof. The PE may also occur in the absence of any known risk factor [2]. In our case, in a young woman with overweight, with PCOS during oral combined hormonal therapy, and with transient immobilisation, VTE occurred. Venous thromboembolism is predominantly a disease of older age (incidence rates increase markedly with age), and it is rare prior to late adolescence [5]. In women, additional risk factors for VTE include combined oral contraceptives, pregnancy, or puerperium [3]. For many years it has been shown that use of COCs was positively associated with VTE risk. The first COCs introduced in the early 1960s contained high doses of oestrogens by today's standards. The oestrogen doses (150 $\mu \mathrm{g}$ mestranol and $50 \mu \mathrm{g}$ ethinyloestradiol (EO), respectively) were quickly associated with an elevated incidence of cardiovascular side effects, especially venous thromboembolism. During the following decades the oestrogen doses were considerably reduced and new molecules of progestins were introduced. These risks may vary according to different characteristics of COCs, such as oestrogen dose, molecule, and type of progestins. Classification of COCs according to generations was irrespective of specific molecule of progestins, but it refers to the timing of the introduction of molecule. Older progestins, called first generation, were approved before the 1970s and include norethindrone and ethynodiol diacetate. Norgestrel and levonorgestrel (LNG) are second-generation COCs, whereas gestodene and desogestrel are third-generation, and the place of norgestimate (NGM) in the third-generation group is debated [6]. A new molecule, drospirenone, differs from the classic progestins in its derivation from spirolactone. The major effect of drospirenone is antimineralocorticoid activity. The affinity of drospirenone for the mineralocorticoid receptor is about five times that of aldosterone, the naturally occurring mineralocorticoid. In addition, drospirenone has no androgenic effect, but does exhibit partial antiandrogenic activity; its antiandrogenic potency is about $30 \%$ of that of cyproterone acetate, the progestin with the most potent antiandrogenic activity [7]. The European Medicines Agency (EMA) published a new classification of COCs in January 2014, based on the molecule of the progestin and not on the generation. Overall, the oestrogenic potency of each hormonal contraceptive depending on both EE doses and progestin molecule explains the level of thrombotic risk. Most studies have reported a significantly increased VTE risk among users of third-generation combined oral contraceptives when compared with users of second-generation pills [6]. The risk of venous thrombosis in second-generation progestogen users was similar to the risk in first-generation users (relative risk $0.9,0.6$ to 1.4 ) [8]. The EMA concluded that COCs containing NGM have the same risk of VTE as that of COCs containing LNG [6]. All combined oral contraceptives have prothrombotic activity resulting from the contribution to factors and inhibitors of coagulation and fibrinolysis, and they can interfere with dynamic haemostatic balance. Generally, the risk of VTE for any woman taking low-dose combined oral contraceptives ( $\leq 35 \mu \mathrm{g}$ EE) is approximately two to three times higher than for non-users, which translates to a very low, acceptable absolute risk for any user when appropriate prescribing guidelines are applied. The question of whether or not the risk of VTE among users of drospirenone-containing COCs is higher again cannot be definitively answered by the available scientific literature because retrospective studies suggest an increased risk, whereas prospective studies show no difference. However, this does, of itself, suggest that any change in absolute risk in drospirenone-containing COCs must remain extremely small in absolute terms [9]. Dinger et al. argue that a drospirenone-containing combined oral contraceptive is associated with similar risk of VTE compared to other combined oral contraceptives [10]. The risk of venous thrombosis is clearly highest during the first three months of use of COC [11], and the increased risk of VTE in patients on combined oral contraceptives decreases after therapy cessation and disappears within three months [12]. In contrast, progestin-only contraception has been considered as generally safe with respect to the risk of cardiovascular disease, including VTE [13]. Beyond that, our patient suffered from PCOS, and epidemiological studies have shown that PCOS is associated with an increased risk VTE. 
Bird et al. found a 1.5-fold increased risk of venous thromboembolism among women with PCOS not taking oral contraceptives and a two-fold increased risk among women with PCOS who were taking combined oral contraceptives [14]. Similar results were obtained by Okoroh et al., i.e. the prevalence of VTE is higher among women with PCOS compared with women without PCOS. PCOS is associated with elevation of plasminogen activator inhibitor (PAI)-1, which is a potent inhibitor of fibrinolysis, and this may be responsible for the increased predisposition to VTE [1]. The last risk factor detected in our patient was long haul ( $>4-6 \mathrm{~h}$ ) travel, which is associated with a slightly (odds ratio < 2) increased risk of VTE [3] resulting in stasis of blood flow in the lower extremities.

The epidemiology of VTE indicates that it is a widespread medical problem because it is the third most common cardiovascular disease after myocardial infarction and stroke. This abnormal condition has a multifactorial aetiology involving interaction between acquired or inherited predispositions to thrombosis and environmental exposures.

\section{Conflict of interest}

The authors declare no conflict of interest.

\section{References}

1. Okoroh EM, Hooper WC, Atrash HK, Yusuf HR, Boulet SL. Is polycystic ovary syndrome another risk factor for venous thromboembolism? United States, 2003-2008. Am J Obstet Gynecol 2012; 207: 377.e1-377.e8.

2. Konstantinides SV, Torbicki A, Agnelli G, Danchin N, Fitzmaurice D, Galiè N, Gibbs JS, Huisman MV, Humbert M, Kucher N, Lang I, Lankeit M, Lekakis J, Maack C, Mayer E, Meneveau N, Perrier A, Pruszczyk P, Rasmussen LH, Schindler TH, Svitil P, Vonk Noordegraaf A, Zamorano JL, Zompatori M; Task Force for the Diagnosis and Management of Acute Pulmonary Embolism of the European Society of Cardiology (ESC). 2014 ESC guidelines on the diagnosis and management of acute pulmonary embolism. Eur Heart J 2014; 35: 3033-3073.

3. Anderson FA, Spencer FA. Risk factors for venous thromboembolism. Circulation 2003; 107 (23 suppl 1): I-9.

4. Piazza G. Beyond Virchow's Triad: does cardiovascular inflammation explain the recurrent nature of venous thromboembolism? Vasc Med 2015; 20: 102-104.

5. Heit JA, Spencer FA, White RH. The epidemiology of venous thromboembolism. J Thromb Thrombolysis 2016; 41: 3-14.

6. Hugon-Rodin J, Gompel A, Plu-Bureau G. Epidemiology of hormonal contraceptives-related venous thromboembolism. Eur J Endocrinol 2014; 171: R221-R230.

7. Sitruk-Ware R. Pharmacology of different progestogens: the special case of drospirenone. Climacteric 2005; 8 supl: 4-12.

8. Stegeman BH, de Bastos M, Rosendaal FR, van Hylckama Vlieg A, Helmerhorst FM, Stijnen T, Dekkers OM. Different combined oral contraceptives and the risk of venous thrombosis: systematic review and network meta-analysis. BMJ 2013; 347: f5298.

9. Bateson D, Butcher BE, Donovan C, Farrell L, Kovacs G, Mezzini T, Baber R. Risk of venous thromboembolism in women taking the combined oral contraceptive: a systematic review and meta-analysis. Austral Fam Phys 2016; 45: 59-64.

10. Dinger J, Möhner S, Heinemann K. Cardiovascular risks associated with the use of drospirenone-containing combined oral contraceptives. Contraception 2016; 93: 378-385.

11. van Hylckama Vlieg A, Helmerhorst FM, Vandenbroucke JP, Doggen CJM, Rosendaal FR. The venous thrombotic risk of oral contraceptives, effects of oestrogen dose and progestogen type: results of the MEGA case-control study. BMJ 2009; 339: b2921.

12. Vinogradova Y, Coupland C, Hippisley-Cox J. Exposure to combined oral contraceptives and risk of venous thromboembolism: a protocol for nested case-control studies using the QResearch and the CPRD databases. BMJ Open 2015; 4: e004499.

13. Eichinger S, Evers JLH, Glasier A, La Vecchia C, Martinelli I, Skouby S, Gianaroli L. Venous thromboembolism in women: a specific reproductive health risk. Hum Reprod Update 2013; 19: 471-482.

14. Bird ST, Hartzema AG, Brophy JM, Etminan M, Delaney JA. Risk of venous thromboembolism in women with polycystic ovary syndrome: a population-based matched cohort analysis. Canad Med Assoc J 2013; 185: E115-E120.

\section{Address for correspondence:}

\section{Łukasz Turek MD}

$2^{\text {nd }}$ Department of Cardiology

Swietokrzyskie Cardiology Centre

ul. Grunwaldzka 45, 25-736 Kielce, Poland

Phone: +48692199654

E-mail: garbit.garbit@interia.pl 